\title{
Applying Physical Education Methods to Skills Teaching of Law Students
}

\author{
Jasper P. Sluijs ${ }^{1}$, Herman Kasper Gilissen ${ }^{2}$, Karin van Look $^{3}$ \\ ${ }^{1}$ Department of International and European Law, Utrecht University School of Law, the \\ Netherlands, ${ }^{2}$ Department of Constitutional, Administrative Law and Legal Theory, Utrecht \\ University School of Law, the Netherlands ${ }^{3}$ Department of Educational Development and \\ Training, Utrecht University School of Social Sciences, the Netherlands.
}

\begin{abstract}
We study to what extent the "constraints-led approach" (CLA) in physical education can also be applied to skills teaching for law students. In the CLA athletes are challenged to finding their own movement solutions in a dynamic setting rather than responding to verbal cues in a fixed environment. Similarly, we experimented with the implicit acquisition of policy analysis skills in law students in preparation for pro bono client work in so-called law clinics. Although the project was cut short due to Covid-19 circumstances, preliminary outcomes suggest students feel better equipped to working with clients. We provisionally conclude that CLA skills teaching has the potential to improve skill acquisition in clinical legal education.
\end{abstract}

Keywords: Skills teaching; law clinics; constraints-led approach. 


\section{Introduction}

Clinical education is a staple of law school curricula. Law clinics allow students to do pro bono legal work with actual clients. As law students typically are unexperienced in pro bono work, we wanted to create a safe learning environment, with room for experimentation and mistakes, while optimizing learning potential. To this end we taught students professional lawyering skills before working with clients, based on insights from the constraints-led approach (CLA) in physical education.

The CLA is a relatively novel methodology in skill acquisition, in which athletes are incentivized to find their own solutions to motor problems by means of manipulation (constraints) in the environment, task or individual. This type of implicit skill acquisition is reported to transfer to improved performance in competition. Similarly, rather than lecturing clinical students about practical skills, we developed a CLA-inspired methodology in which clinical students independently acquired policy analysis skills before commencing a clinic in which they assisted local municipalities in developing or implementing climate adaptation policies.

This paper chronicles our experiences developing and executing a CLA-inspired training program for law students in the "Water \& Climate Law" clinic, and our preliminary findings. To this end, we will first outline how our research project is grounded in clinical legal education and the CLA. We will then explore our aims for this research project, and the methodology by which we have executed and evaluated it. This will lead into an analysis of our findings and suggestions for follow-up research.

\section{Context}

Law clinics allow students to do pro bono work for real clients as part of their law school curriculum. This pro bono work, however, requires practical lawyering skills. The CLA is a novel skills acquisition method coming from the field of physical education and motor learning.

\subsection{Clinical Legal Education}

A law degree is a professional degree, and qualifies graduates to apply for bar membership and eventually practice as an attorney. Like with any professional in a regulated profession, rights come with responsibilities for the practicing lawyer. It is therefore that a purely academic legal education may not be the most optimal preparation for practice. The ambition to better prepare law students for practice led to the development of law clinics in US law schools from the 1930 onwards (Carey, 2002), for fear law students become "like future horticulturalists confining their studies to cut flowers, like architects who study pictures of 
buildings and nothing else, [or] prospective dog breeders who never see anything but stuffed dogs.” (Frank, 1933)

Since, a tradition of law clinics has emerged across the world, in which students undertake pro bono lawyering work for real clients under the tutelage of professors with experience in practice. Typically law clinics have a social justice component, by offering legal work to disenfranchised people or institutions (Barry et al., 2011). Moreover, clinics tend to take place in the vicinity of the law school, allowing for community-based pro bono lawyering (Tokarz et al., 2008).

While law clinics offers students learning by experience (Wizner, 2001), the responsibility towards clients also calls for skills training in students - think of communication, time management, presentation and professional writing skills. While this type of skills training has broadly been regarded as crucial for the success of clinical education for law students, no common methodology has emerged (Kruse, 2013). We propose to experiment with a relatively novel method for skill acquisition in physical education.

\subsection{The Constraints-Led Approach}

The CLA stems from pedagogical science as a means to study motor learning in children (Wade \& Whiting, 1986). As a theorem, the CLA has traveled to physical education and motor development since, and has offered a new approach to skills acquisition in sports.

The traditional approach to skills acquisition in sports prescribes that coaches should encourage athletes towards perfect technical execution in isolation, which will then transfer to optimal performance in competition (Fitts \& Posner, 1979). This typically involves repetitive drills — dribbeling a basketball between cones leading up to a jump-shot — coupled with explicit verbal feedback: "tuck your elbow, and again."

The CLA poses that the supposed transfer from practice to competition in this traditional approach to skills acquisition does not materialize. Therefore there is little use for striving towards perfect technical execution in isolation (Renshaw, Chow, et al., 2010). In the CLA, rather, athletes are challenged to find their own movement solutions in a dynamic setting, through manipulation of tasks, environment and individual conditions. This involves nonspecific drills closely resembling competition, with few verbal cues by coaches (Davids et al., 2008; Renshaw, Davids, et al., 2010). For example: a basketball drill with defenders instead of cones that incentivizes rather than tells the athlete to take a jump-shot, by limiting the playing field to the perimeter. Randomized controlled trials show better performance in athletes following CLA training over traditional skill acquisition methods (Gray, 2020). 


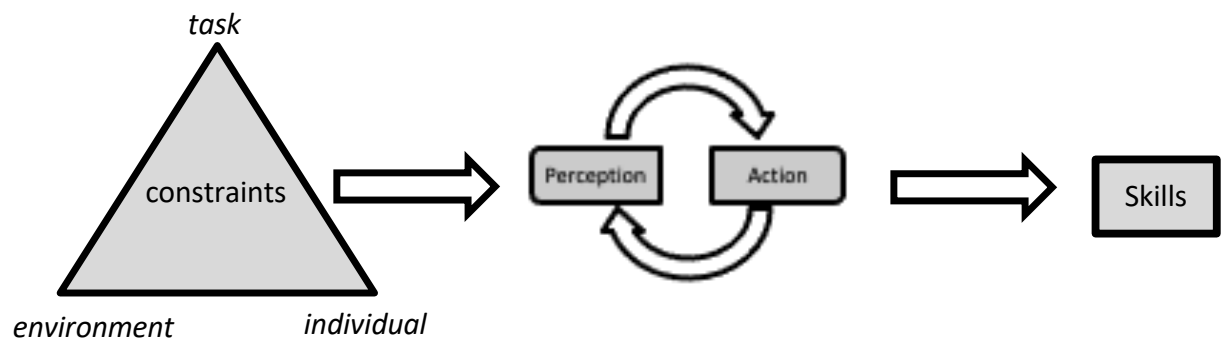

Figure 1: the CLA fosters skill acquisition by manipulation of task, environment and individual conditions, leading to sensory perception in action

\section{Aims and Approach of the Research}

We have set up a project to apply insights from the CLA to clinical legal education. The starting point for this project was our experience that law students weren't properly prepared for working with real clients in law clinics. This manifested itself on two levels. First, students themselves reported feeling insecure and ill-equipped to dealing with 'real' cases and clients, mainly due to inexperience and a fear of making mistakes. Second, as professors we found students to be hard-wired to treat clinical cases like abstract exam questions to be solved in isolation, rather than real problems of real people that need to be involved in the project. Moreover, a unlike an exam a clinical project does not necessarily lead to one correct 'answer.'

Similar to the traditional approach to motor learning in sports mentioned above, academic legal skills teaching often pre-supposes transfer from verbal instruction to practical execution (Binder \& Bergman, 2003). Better preparing graduates for practice by skills teaching and the optimal methodology to teach skills has become a hotly debated topic in legal academia (Kruse, 2013). At our law school, this has led to the establishment of a so-called "Legal Skills Academy," organizing lectures and descriptive 1-pagers about professional and academic skills. As part of this ongoing debate on skill teaching for law students, we have experimented with professional skill acquisition in a law clinic, modeled on the CLA methodology.

\subsection{Aims: Effective Analytical Skills Acquisition}

Of the many skills that students need to excel in a law clinic, we decided to focus on the analytical skills required for client work. Similarly to law practice, clients in law clinics often have a hard time explaining the issue they face - they are not trained lawyers, after all. Acquiring the analytical skill to abstract a client's situation, in our view, would better prepare students for a law clinic. 
Instead of lecturing students on analytical skills, we set out to incentivize students to themselves develop a method to analyze a client's policy program, and to abstract this into a coherent and tractable project. This was done in preparation for our "Water \& Climate Law" clinic, in which students would advise 5 participating municipalities on developing and/or implementing local climate adaptation policies. This clinic is the final compulsory course in our 1-year LLM-program in Environmental Law. After having finished this course and having written their LLM thesis, most students start applying for jobs.

\subsection{Methods}

We developed a day-long training session culminating into the students' first meeting with representatives of the municipalities. In this training session we led students through a series of scenarios to be discussed in groups, with little ex ante instruction.

First, students were given documents on an existing municipal policy program to prevent flooding by excessive rain in low-lying neighborhoods. Given the complexity of this program, students were divided into small groups and asked to figure out:

- Question 1:

- Group 1: what does this program do?

- Group 2: why has this program been instantiated?

○ Group 3: where is the program situated, and what are the particularities of this location?

- Group 4: when will this program take place?

- Group 5: who (which stakeholders) are involved in this program?

○ Group 6: how (using what instruments) will this program be executed?

- Question 2: what other questions would you wish to ask to figure out the key elements of this program?

Students would prepare for 15 minutes, and present their findings plenarily. The aim of this exercise was for the students to collectively answer question 2, incentivizing them to jointly develop a set of standard questions that can be asked to analyze any given policy program: what, why, where, when, who and how-or 5W1H in short (Bromell, 2017).

Second, students were again divided into small groups and given a separate (fictional) scenario in which a problem occurred during the implementation of the previously introduced policy program. Students were asked to abstract this problem to the level of tensions between the previously developed basic questions, for instance:

When the city council intends to de-fund the flooding prevention program after a prolonged drought period, this points out a tension between the "what" and "why" question. 
Students were asked to present their scenario plenarily, and reflect on how they abstracted it into a basic tension. The aim of this exercise was to make students realize that most policy implementation problems can be translated into tensions between the basic components of a policy proposal.

In both of these exercises we manipulated the task and environment to incentivize the students to develop their own solutions in policy analysis and implementation, rather than lecturing them on the $5 \mathrm{~W} 1 \mathrm{H}$ method in policy analysis and the basic tensions between $5 \mathrm{~W} 1 \mathrm{H}$ components (Bromell, 2017). Our hypothesis was that this CLA preparation would lead to positive outcomes in students' self-perceived level of preparedness for the environmental law clinic. We would test this hypothesis by means of a perceived efficacy survey immediately following the training session and a perceived effectiveness survey after completion of the clinic.

\section{Results}

The Water \& Climate Law clinic was a 5 EC course that took place at Utrecht University School of Law (the Netherlands) from February until May of 2020. 14 Master's level students participated, and divided in groups assisted 5 municipalities in the Utrecht province in the development and implementation of climate adaptation policies. The students' involvement was part of a larger project about climate resilience in residential areas in the Utrecht region funded by the Dutch National Delta Program (Kennisportaal Klimaatadaptatie, 2016).

Based on the qualitative perceived efficacy survey immediately following the training session $(\mathrm{N}=14)$, we find that students felt well prepared for working with the municipalities after the training sessions. Students reported:

- Being able to systematically analyze a policy program at the start of a project

- Being able to identify common problems that clients have run into when approaching outside counsel

- $\quad$ Being able to depart from pure legal analysis and consider the broader, non-legal context in which clients operate

This latter finding was not envisioned, but at the same time not entirely unforeseen. This outcome partially mitigates the situation described in section 3 above of students being "hard-wired to treat clinical cases like abstract exam questions."

As so often in 2020, the Covid-19 epidemic led to unforeseen circumstances for the Water \& Climate Law clinic. Lockdown and quarantine requirements complicated the clinical projects significantly, leading us to terminate the formal evaluation of the clinic - including the ex post effectiveness survey. Notwithstanding the encouraging outcome of the initial qualitative 
survey, therefore, we do not have the data to definitively report on the effectiveness of our CLA methodology.

\section{Conclusions}

The findings of our experiment are limited but promising: as hypothesized, participating students report being able to better analyze a policy program and the typical problems a policy program may run into. Moreover, students report being able to better relate to the not purely legal context in which a client operates. Lastly, students report to feel less insecure about working with 'real' clients.

Given these qualitative results we preliminarily conclude that CLA skills teaching has the potential to improve skill acquisition in clinical legal education. We feel encouraged to iterate on our initial findings and develop a more quantitative study on the effectiveness of constraints-based teaching in law clinics. We therefore intend to run follow-up surveys with a new group of students in the clinic once on-campus teaching resumes.

\section{References}

Barry, M. M., Camp, A. R., Johnson, M. E., \& Klein, C. F. (2011). Teaching Social Justice Lawyering: Systematically including Community Legal Education in Law School Clinics. Clinical Law Review, 18(2), 401-458.

Binder, D. A., \& Bergman, P. (2003). Taking Lawyering Skills Training Seriously Symposium: The 25th Anniversary of Gary Bellow's \& Bea Moulton's the Lawyering Process. Clinical Law Review, 10(1), 191-220.

Bromell, D. (2017). Doing Policy Analysis. In D. Bromell (Ed.), The Art and Craft of Policy Advising: A Practical Guide (pp. 83-124). Springer International Publishing.

Carey, S. V. (2002). An Essay on the Evolution of Clinical Legal Education and Its Impact on Student Trial Practice History of the Trial. University of Kansas Law Review, 51(3), 509-542.

Davids, K., Button, C., \& Bennett, S. (2008). Dynamics of Skill Acquisition: A Constraintsled Approach. Human Kinetics.

Fitts, P. M., \& Posner, M. I. (1979). Human Performance. Greenwood Press.

Frank, J. (1933). Why Not a Clinical Lawyer-School? University of Pennsylvania Law Review, 81(8), 907.

Gray, R. (2020). Comparing the constraints led approach, differential learning and prescriptive instruction for training opposite-field hitting in baseball. Psychology of Sport and Exercise, 51, 101797.

Kennisportaal Klimaatadaptatie. (2016). National climate adaptation strategy 2016 (NAS) [Overzichtspagina]. Spatial Adaptation. https://klimaatadaptatienederland.nl/en/policyprogrammes/nas/ 
Kruse, K. R. (2013). Legal Education and Professional Skills: Myths and Misconceptions about Theory and Practice Symposium: The State and Future of Legal Education. McGeorge Law Review, 45(1), 7-50.

Renshaw, I., Chow, J. Y., Davids, K., \& Hammond, J. (2010). A constraints-led perspective to understanding skill acquisition and game play: A basis for integration of motor learning theory and physical education praxis? Physical Education and Sport Pedagogy, 15(2), 117-137. https://doi.org/10.1080/17408980902791586

Renshaw, I., Davids, K., \& Savelsbergh, G. J. P. (2010). Motor Learning in Practice: A Constraints-Led Approach. Routledge.

Tokarz, K., Cook, N. L., Brooks, S., \& Blom, B. B. (2008). Conversations on Community Lawyering: The Newest (Oldest) Wave in Clinical Legal Education New Directions in Clinical Legal Education. Washington University Journal of Law and Policy, 28, 359402.

Wade, M. G., \& Whiting, H. T. A. (1986). Motor Development in Children: Aspects of Coordination and Control. Springer Netherlands.

Wizner, S. (2001). The Law School Clinic: Legal Education in the Interests of Justice. Fordham Law Review, 70(5), 1929-1938. 